\title{
Role of Biochemical Nutritional Parameters as Predictors of Postoperative Morbidity in Major Spine Surgeries
}

\author{
Deepak Sugumar, Justin Arockiaraj, Rohit Amritanand, Kenny S. David, Venkatesh Krishnan \\ Spinal Disorders Surgery Unit, Department of Orthopaedics, Christian Medical College, Vellore, India
}

\begin{abstract}
Study Design: Prospective cohort study.
Purpose: To evaluate the association between nutritional parameters related to postoperative surgical site infections and duration of hospital stay and intensive care unit (ICU) stay in patients undergoing major spine surgery.

Overview of Literature: Malnutrition is highly prevalent in surgical patients. Malnourished patients are considered to be at higher risk for postoperative morbidity and mortality due to impaired wound healing, delayed inflammation, impaired fibroblast proliferation, and collagen synthesis. Decreased lymphocyte count also impairs the ability of the immune system to eradicate or prevent infection, which predisposes these patients to infections. However, this association between malnutrition and postoperative morbidity is not consistent across studies, thus necessitating further investigation.

Methods: The values of serum albumin, prealbumin, total lymphocyte counts, and transferrin were documented preoperatively and postoperatively on day 5 for all patients undergoing major spine surgery (surgery involving instrumentation of at least three motion segments). In addition, patients' surgical wound healing status, duration of hospital stay, and duration of ICU stay in the postoperative period were documented. Finally, the statistical correlation between the nutritional markers and these complications was determined. Results: Low postoperative prealbumin levels was significantly associated with increased complication rates. ICU stay demonstrated a statistically significant association with low postoperative albumin, prealbumin, and transferrin levels. Similarly, we observed that low postoperative albumin and prealbumin levels could significantly predict the need for prolonged hospital stay in patients undergoing major spine surgery.

Conclusions: The magnitude of the decrease in nutritional status due to surgery with respect to albumin and prealbumin levels is a significant $(p<0.05)$ predictor of wound-related complications, rather than a single nutritional parameter evaluated at a point of time.
\end{abstract}

Keywords: Malnutrition; Albumin; Prealbumin; Lymphocyte count; Transferrin

\section{Introduction}

The importance of nutrition for surgery was first recognized in 1930s when malnutrition was found to have adverse impact on surgical outcomes. Studley [1] found a direct relationship between preoperative weight loss and postoperative mortality rate, independent of factors such as age, impaired cardiorespiratory function, and type

Received Apr 19, 2020; Revised Apr 28, 2020; Accepted May 21, 2020

Corresponding author: Justin Arockiaraj

Spinal Disorders Surgery Unit, Department of Orthopaedic Surgery, Christian Medical College, Vellore, Tamilnadu, 632004, India

Tel: +91-94431143800, Fax: +91-4162232054, E-mail: svjustin@cmcvellore.ac.in 
of surgery. The importance of nutritional depletion as a major determinant of the development of postoperative complications was subsequently confirmed by Giner et al. [2]. In 1936, Cuthbertson [3] described the adverse effects of malnutrition on his patients, which made orthopedic surgeons aware of this relationship.

More than $40 \%$ of hospitalized patients have been reported to be malnourished, and undernourishment has been estimated in $4.3 \%$ of community population [4]. Preoperative malnutrition has been associated with numerous poor postsurgical outcomes (infection, acute kidney injury, increased hospital/intensive care unit [ICU] stay, revision surgeries, and mortality) [5]. It is believed that malnutrition predisposes patients to surgical site infections by impairing the process of wound healing and prolonging inflammation through impairment of fibroblast proliferation and collagen synthesis [6-8]. Klein et al. [9] found that patients who were malnourished preoperatively had a significantly higher risk for infection and postoperative complications. Similarly, Jevsevar and Karlin [10] observed that malnourished patients had a significantly higher rate of infection and longer length of hospital stay. Both these studies defined preoperative malnutrition as a serum albumin level $<3.5 \mathrm{~g} / \mathrm{dL}$ or a total lymphocyte count (TLC) $<1,500 / \mathrm{mm}^{3}$. A decreased lymphocyte count impairs the ability of the immune system to eradicate or prevent infection, thus predisposing malnourished patients to infections [11].

Nevertheless, not all studies have consistently demonstrated this association. In a systematic review of literature, Schuster et al. [12] found that only two of the four published studies reported an association between preoperative malnutrition and surgical site infection. In case-control studies, both Apisarnthanarak et al. [13] and Klekamp et al. [14] did not find an increased incidence of malnourishment in patients who developed postoperative infections. Furthermore, in a retrospective multicenter case-control study conducted by Sponseller et al. [15] at Aarhus University Hospital, Denmark, no statistically significant association was found between undernutrition and increased risk for infections. Considering this inconsistent evidence and the fact that there is a paucity of literature regarding the outcome of major spine surgeries with respect to nutrition, this study was conducted, to evaluate the association between nutritional parameters related to postoperative surgical site infections and duration of ICU stay and hospital stay in patients undergoing major spine surgery.

\section{Materials and Methods}

This study was conducted at the Spinal Disorders Surgery Unit, Department of Orthopaedics, Christian Medical College, Vellore, India. We included all patients who were treated surgically with fusion of more than three levels for any pathological condition between June 2017 and June 2019. IRB approval was obtained as per the institution policy at the Christian Medical College, Vellore, India.

\section{Participants}

The inclusion criteria were as follows: (1) patients undergoing $\geq$ three-level instrumentation/fusion surgery at the thoracic, lumbar, or lumbosacral level and (2) patients aged $18-80$ years. The exclusion criteria were as follows: (1) renal dysfunction, (2) corticosteroid therapy, (3) liver dysfunction, (4) age $<18$ and $>80$ years, (5) previous or revision surgery within 2 months of first surgery, and (6) previous radiotherapy at the same surgical site.

This was a prospective study conducted to determine the effect of nutritional status on the outcomes of major spine surgeries. Patients who were planned for a spine surgery involving instrumentation of three or more levels, fulfilling the inclusion criteria, and those who have consented for the study were included. All patients were evaluated clinically and biochemically with nutritional parameters, which includes albumin, prealbumin, transferrin, total and differential lymphocyte counts preoperatively. Postoperatively also both clinical and nutritional biochemical parameters were evaluated and recorded. Clinically, surgical site infections, wound healing issues, ICU stay, and length of hospital stay were documented. Biochemical parameters such as prealbumin, TLC, albumin, and transferrin levels were evaluated on postoperative day 5 . The biochemical data and their relationship with clinical outcomes were analyzed statistically.

\section{Statistical analysis}

The parameters albumin, transferrin, prealbumin, and TLC were investigated at two different time points. Based on the assumption, repeated-measures analysis of variance (ANOVA) or multivariate ANOVA was used to identify the change over time in the biochemical nutritional parameters. The changes in biochemical parameters from baseline to post-baseline were analyzed using a paramet- 
Table 1. Prevalence of malnutrition in preoperative and postoperative patients

\begin{tabular}{lccc} 
Indices of malnutrition & $\begin{array}{c}\text { No. of patients with } \\
\text { preoperative malnutrition }\end{array}$ & $\begin{array}{c}\text { No. of patients with } \\
\text { postoperative malnutrition }\end{array}$ & $\begin{array}{c}\text { No. of patients with new onset } \\
\text { postoperative malnutrition }\end{array}$ \\
\hline Albumin $\leq 3.5 \mathrm{~g} / \mathrm{dL}$ & 45 & 130 & 85 (52) \\
\hline Total lymphocyte $\leq 1,500$ cells $/ \mathrm{mm}^{3}$ & 64 & 125 & $61(37)$ \\
\hline Prealbumin $\leq 15 \mathrm{mg} / \mathrm{dL}$ & 30 & 81 & $51(31)$ \\
\hline Transferrin $\leq 204 \mathrm{mg} / \mathrm{dL}$ & 49 & 137 & $88(54)$ \\
\hline Average & $47(29)$ & $118(72)$ & $71.25(44)$ \\
\hline
\end{tabular}

Values are presented as number or number $(\%)$.

ric paired $t$-test or a nonparametric Wilcoxon signedrank test. The Shapiro-Wilk or Kolmogorov-Smirnov test or histogram with summary values was used to test the hypothesis of normal distribution. The chi-square or Fisher's exact test was applied to determine the association between categorical variables. All tests were two-sided at $\alpha=0.05$ level of significance. All analyses were conducted using the IBM SPSS software ver. 21.0 (IBM Corp., Armonk, NY, USA). A $p$-value of $\leq 0.05$ was considered statistically significant.

\section{Results}

\section{Patient demographics}

The study population consisted of 162 patients during the 2 -year study period. The clinical and biochemical parameters of all patients were analyzed. Nutritional assessments during the preoperative period and the postoperative period on day 5 were conducted for all patients. The mean age of the study patients was 44 years, with a range of $18-76$ years. There were 103 males (63\%) and 59 females (36\%). All the four nutritional parameters included in this study were investigated separately with respect to wound-related complications, duration of hospital stay, and ICU stay. Albumin level $\leq 3.5 \mathrm{~g} / \mathrm{dL}$, absolute lymphocyte count $\leq 1,500$ cells $/ \mathrm{mm}^{3}$, prealbumin level $\leq 15 \mathrm{mg} / \mathrm{dL}$, and transferrin level $\leq 204 \mathrm{mg} / \mathrm{dL}$ were considered to indicate malnutrition (based on normal biochemical values).

The prevalence of malnutrition in our study differed according to the nutritional parameters. Preoperatively, the prevalence of malnutrion was as high as 39\% (64 patients) when malnutrition was considered with respect to TLC and as low as $18 \%$ (30 patients) when considered with respect to prealbumin levels. Postoperatively, an average of $44 \%$ of patients had newly diagnosed malnutrition (Table 1).
Table 2. Chi-square test of association between preoperative malnutrition and incidence of complication

\begin{tabular}{lcccc}
$\begin{array}{l}\text { Preoperative indices of } \\
\text { malnutrition }\end{array}$ & $\begin{array}{c}\text { Patients with } \\
\text { complications }\end{array}$ & \begin{tabular}{c} 
No. of patients \\
without \\
\cline { 2 - 3 } complications
\end{tabular} \\
\hline Albumin $\leq 3.5 \mathrm{~g} / \mathrm{dL}$ & 6 & 0.780 & 39 \\
\hline Total lymphocyte $\leq 1,500$ cells $/ \mathrm{mm}^{3}$ & 10 & 0.132 & 54 \\
\hline Prealbumin $\leq 15 \mathrm{mg} / \mathrm{dL}$ & 4 & 0.914 & 26 \\
\hline Transferrin $\leq 204 \mathrm{mg} / \mathrm{dL}$ & 6 & 0.99 & 43 \\
\hline
\end{tabular}

Table 3. Chi-square test of association between preoperative indices of good nutrition and incidence of complications

\begin{tabular}{|c|c|c|c|}
\hline \multirow{2}{*}{$\begin{array}{l}\text { Preoperative indices of good } \\
\text { nutrition }\end{array}$} & \multicolumn{2}{|c|}{$\begin{array}{l}\text { Patients with } \\
\text { complications }\end{array}$} & \multirow{2}{*}{$\begin{array}{l}\text { No. of patients } \\
\text { without } \\
\text { complications }\end{array}$} \\
\hline & No. & $p$-value & \\
\hline Albumin $\geq 3.5 \mathrm{~g} / \mathrm{dL}$ & 18 & 0.7802 & 144 \\
\hline Total lymphocyte $\geq 1,500$ cells $/ \mathrm{mm}^{3}$ & 8 & 0.2218 & 90 \\
\hline Prealbumin $\geq 15 \mathrm{mg} / \mathrm{dL}$ & 14 & 0.9146 & 118 \\
\hline Transferrin $\geq 204 \mathrm{mg} / \mathrm{dL}$ & 12 & 0.9906 & 101 \\
\hline
\end{tabular}

None of the biochemical nutritional markers showing low levels in the preoperative period demonstrated a significant association with increased rate of complications ( $p>0.05)$ (Table 2). Moreover, none of the biochemical nutritional markers showing normal levels in the preoperative period were significantly associated with increased rate of complications $(p>0.05)$ (Table 3$)$. We also found that low levels of albumin, TLC, and transferrin in the postoperative period showed no significant association with complications. However, a low prealbumin level in the postoperative malnutrition group was significantly associated with increased rate of complications $(p=0.05)$ (Table 4). In addition, none of the biochemical nutritional markers showing normal levels in the postoperative peri- 
Table 4. Chi-square test of association between postoperative malnutrition and incidence of complication

\begin{tabular}{|c|c|c|c|}
\hline \multirow{2}{*}{ Indices of malnutrition } & \multicolumn{2}{|c|}{$\begin{array}{l}\text { Patients with } \\
\text { complications }\end{array}$} & \multirow{2}{*}{$\begin{array}{l}\text { No. of patients } \\
\text { without } \\
\text { complications }\end{array}$} \\
\hline & No. & $p$-value & \\
\hline Albumin $\leq 3.5 \mathrm{~g} / \mathrm{dL}$ & 17 & 0.196 & 113 \\
\hline Total lymphocyte $\leq 1,500$ cells $/ \mathrm{mm}^{3}$ & 16 & 0.36 & 109 \\
\hline Prealbumin $\leq 15 \mathrm{mg} / \mathrm{dL}$ & 15 & 0.05 & 66 \\
\hline Transferrin $\leq 204 \mathrm{mg} / \mathrm{dL}$ & 17 & 0.314 & 118 \\
\hline
\end{tabular}

Table 5. Chi-square test of association between postoperative indices of good nutrition and complication

\begin{tabular}{|c|c|c|c|}
\hline \multirow{2}{*}{ Indices of good nutrition } & \multicolumn{2}{|c|}{$\begin{array}{l}\text { Patients with } \\
\text { complications }\end{array}$} & \multirow{2}{*}{$\begin{array}{l}\text { No. of patients } \\
\text { without } \\
\text { complications }\end{array}$} \\
\hline & No. & $p$-value & \\
\hline Albumin $\geq 3.5 \mathrm{~g} / \mathrm{dL}$ & 1 & 0.1968 & 31 \\
\hline Total lymphocyte $\geq 1,500$ cells $/ \mathrm{mm}^{3}$ & 2 & 0.3373 & 35 \\
\hline Prealbumin $\geq 15 \mathrm{mg} / \mathrm{dL}$ & 3 & 0.06 & 78 \\
\hline Transferrin $\geq 204 \mathrm{mg} / \mathrm{dL}$ & 1 & 0.3143 & 26 \\
\hline
\end{tabular}

Table 6. Drop in nutritional status and complications

\begin{tabular}{lcrcc} 
& \multicolumn{4}{c}{ Mean difference in preop and postop nutritional indices } \\
\cline { 2 - 5 } Variable & Albumin & Total lymphocyte & Prealbumin & Transferin \\
Complication & 1.06 & $1,025.33$ & 9.72 & 68.61 \\
\hline No complication & 0.76 & 810.51 & 7.67 & 58.25 \\
Correlation & 0.18 & 0.08 & 0.12 & 0.09 \\
$p$-value & 0.01 & 0.33 & 0.04 & 0.25 \\
\hline
\end{tabular}

Preop, preoperative; Postop, postoperative.

od showed a significant association with increased rates of complications $(p>0.05)$ (Table 5). We found that the magnitude of decrease in the nutritional status after surgery with respect to serum albumin and serum prealbumin levels had statistically significant association with complications (Table 6). None of the preoperative nutritional parameters could significantly predict the need for ICU admission in patients undergoing major spine surgery (Table 7). A statistically significant association was observed between low postoperative albumin, prealbumin, and transferrin levels and ICU stay in the postoperatively malnourished group (Table 8). Furthermore, a low preoperative lymphocyte count and low postoperative albumin
Table 7. Chi-square test of association between preoperative malnutrition and incidence of ICU stay

\begin{tabular}{|c|c|c|c|}
\hline \multirow{2}{*}{$\begin{array}{l}\text { Preoperative indices of } \\
\text { malnutrition }\end{array}$} & \multicolumn{2}{|c|}{$\begin{array}{l}\text { Patients with ICU } \\
\text { stay postoperatively }\end{array}$} & \multirow{2}{*}{$\begin{array}{l}\text { No. of patients } \\
\text { without } \\
\text { ICU stay }\end{array}$} \\
\hline & No. & $p$-value & \\
\hline Albumin $\leq 3.5 \mathrm{~g} / \mathrm{dL}$ & 12 & 1 & 33 \\
\hline Total lymphocyte $\leq 1,500$ cells $/ \mathrm{mm}^{3}$ & 16 & 0.809 & 48 \\
\hline Prealbumin $\leq 15 \mathrm{mg} / \mathrm{dL}$ & 7 & 0.8321 & 23 \\
\hline Transferrin $\leq 204 \mathrm{mg} / \mathrm{dL}$ & 14 & 0.873 & 35 \\
\hline
\end{tabular}

ICU, intensive care unit.

Table 8. Chi-square test of association between postoperative malnutrition and incidence of ICU stay

\begin{tabular}{lccc}
\multirow{2}{*}{$\begin{array}{l}\text { Postoperative indices of } \\
\text { malnutrition }\end{array}$} & $\begin{array}{c}\text { Patients with ICU stay } \\
\text { postoperatively }\end{array}$ & $\begin{array}{c}\text { No. of patients } \\
\text { without } \\
\text { ICU stay }\end{array}$ \\
\cline { 2 - 3 } & No. & $p$-value & \\
\hline Albumin $\leq 3.5 \mathrm{~g} / \mathrm{dL}$ & 42 & 0.001 & 88 \\
\hline Total lymphocyte $\leq 1,500$ cells $/ \mathrm{mm}^{3}$ & 32 & 0.962 & 93 \\
\hline Prealbumin $\leq 15 \mathrm{mg} / \mathrm{dL}$ & 30 & 0.004 & 51 \\
\hline Transferrin $\leq 204 \mathrm{mg} / \mathrm{dL}$ & 41 & 0.025 & 94 \\
\hline
\end{tabular}

ICU, intensive care unit.

Table 9. Preop nourishment vs. average duration of hospital stay

\begin{tabular}{lccc} 
& \multicolumn{2}{c}{$\begin{array}{c}\text { Preop nutritional status vs. average } \\
\text { duration of hospital stay (day) }\end{array}$} \\
\cline { 2 - 3 } Indicators of malnutrition & \begin{tabular}{c} 
Malnourished \\
\cline { 2 - 3 }
\end{tabular} & Well nourished \\
\cline { 2 - 3 } Albumin $\leq 3.5 \mathrm{~g} / \mathrm{dL}$ & 15 & 0.06 & 12 \\
\hline Total lymphocyte $\leq 1,500$ cells $/ \mathrm{mm}^{3}$ & 14 & 0.027 & 11 \\
\hline Prealbumin $\leq 15 \mathrm{mg} / \mathrm{dL}$ & 14 & 0.140 & 12 \\
\hline Transferrin $\leq 204 \mathrm{mg} / \mathrm{dL}$ & 14 & 0.082 & 12 \\
\hline Preop, prope & & & \\
\hline
\end{tabular}

Preop, preoperative.

Table 10. Postop nourishment vs. average duration of hospital stay

\begin{tabular}{|c|c|c|c|}
\hline \multirow{3}{*}{ Indicators of malnutrition } & \multicolumn{3}{|c|}{$\begin{array}{l}\text { Postop nutritional status vs. average } \\
\text { duration of hospital stay (day) }\end{array}$} \\
\hline & \multicolumn{2}{|c|}{ Malnourished } & \multirow{2}{*}{ Well nourished } \\
\hline & No. & $p$-value & \\
\hline Albumin $\leq 3.5 \mathrm{~g} / \mathrm{dL}$ & 13 & 0.0002 & 10 \\
\hline Total lymphocyte $\leq 1,500$ cells $/ \mathrm{mm}^{3}$ & 12 & 0.846 & 13 \\
\hline Prealbumin $\leq 15 \mathrm{mg} / \mathrm{dL}$ & 14 & 0.033 & 11 \\
\hline Transferrin $\leq 204 \mathrm{mg} / \mathrm{dL}$ & 13 & 0.285 & 11 \\
\hline
\end{tabular}

Postop, postoperative. 
and prealbumin levels could significantly predict the need for prolonged hospital stay in patients undergoing major spine surgery (Tables 9, 10).

\section{Complications}

A total of 18/162 patients (11\%) had wound-related complications, which includes eight patients with superficial wound infection or delayed wound healing and $10 \mathrm{pa}-$ tients with deep infection. All patients with deep wound infection required wound debridement followed by thorough wash and closure.

\section{Discussion}

\section{Incidence of malnutrition}

The incidence of malnutrition according to the biochemical parameters (albumin level $\leq 3.5 \mathrm{~g} / \mathrm{dL}$ and TLC $\leq 1,500$ cells $/ \mathrm{mm}^{3}$ ) was $39.5 \%$ (64 patients), which was comparable to that reported in other studies [16]. There were 118 patients $(72 \%)$ with malnutrition on postoperative day 5 . To our knowledge, no study has reported the prevalence of malnutrition in the immediate postoperative period.

In a prospective study conducted by Jensen et al. [17] on 129 patients, it was observed that trauma and major surgery resulted in the highest incidence of malnutrition (58.6\%), and suboptimal nutrition correlated with an increased risk of complications, including sepsis, wound healing, and pulmonary issues.

\section{Incidence of complications}

The incidence of wound-related complications in our study group was $11 \%$. Different studies published in the literature have reported that the incidence of surgical site infections following spine surgery which ranges from $0.5 \%$ to $18.8 \%$ [18-20]. Such wide-ranging results from different reports are most probably due to significant variations in operative factors such as the use of implants, case complexity, and the surgical approach itself. In addition, in some cases, discitis and superficial skin infections may be self-limited and may not be reported to the surgeon. As the majority of our study patients had etiologies that required instrumentation of three or more motion segments and complex surgeries, the higher rates of surgical site infections found in our study could be justified.
The rate of surgical complications and infection is dependent on the etiology. Smith et al. [16] evaluated 108,419 cases of spine surgery from the Scoliosis Research Society morbidity and mortality database and reported that the overall rates of postoperative superficial and deep wound infections were $0.8 \%$ and $1.3 \%$, respectively. For both adult and pediatric patients, the rates of postoperative wound infection were lowest for procedures performed for degenerative spine diseases and highest for procedures performed for spine deformities. Procedures associated with spinal fusion or implants had a significantly higher rate of postoperative wound infection, likely reflective of the greater complexity and the associated risk of cases that require fusion or the use of implants. Compared with the traditional open approach, the use of a minimally invasive approach was associated with a lower rate of infection for lumbar discectomy and transforaminal lumbar interbody fusion.

\section{Malnutrition and complications}

In the present study, we observed that none of the preoperative nutritional parameters had a significant relationship with increased risk of wound-related complications. Although most of the studies published in the literature demonstrate an association between these serologic laboratory values and infection, some studies such as the retrospective multicenter case-control study of 210 cases of neuromuscular scoliosis surgeries conducted by Sponseller et al. [15] found no statistically significant association between undernutrition, as defined by a serum albumin level $<3.5 \mathrm{~g} / \mathrm{dL}$ and a TLC $<1,500 \mathrm{cells} / \mathrm{mm}^{3}$, and increased risk of infection.

However, Jevsevar and Karlin [10] reported that a preoperative albumin level $<3.5 \mathrm{~g} / \mathrm{dL}$ and a TLC $<1,500$ cells/ $\mathrm{mm}^{3}$ were associated with higher rates of overall infection in 44 patients with cerebral palsy after spinal surgery. Similarly, in a review of patients undergoing elective spine surgery, Beiner et al. [21] reported higher rates of postoperative infection and poor wound healing in patients with a serum albumin level $<3.5 \mathrm{~g} / \mathrm{dL}$ and a TLC $<1,500$ cells/ $\mathrm{mm}^{3}$.

In our study, we found a significant correlation $(p=0.05)$ between postoperative low prealbumin levels and increased rate of complications (Table 4). Prealbumin has a short half-life of 2-3 days compared to that of albumin of 14-20 days. The short half-life of prealbumin is reflected 
as an acute decrease in its level compared with other parameters, and its relationship with increased rates of complication indicates that the decrease in the nutritional status of patients following surgery has a significant correlation with the rate of complications [22]. Similar to the abovementioned findings, we detected a significant correlation between "decrease in nutritional parameters" postoperatively and rate of complications (Table 6). The decrease in nutritional parameters was measured by the difference between preoperative and postoperative nutritional parameters. We found a significant correlation between the reduction in albumin $(1.0 \mathrm{~g} / \mathrm{dL})$ and prealbumin $(9.7 \mathrm{mg} / \mathrm{dL})$ levels and the increased complication rates. Major spine surgeries cause a catabolic breakdown of body nutritional reserves resulting in a status of malnutrition. This change in nutritional status can lead to complications due to impairment in immunity and healing potential [12].

Analysis of the pre- and postoperative nutritional status in relation to the incidence of complications, revealed statistically significant result with low postoperative prealbumin (Table 4). This finding further supported the fact that the magnitude of the decrease in nutritional status was a more important predictor of complications, rather than a single nutritional parameter.

In patients undergoing major spine surgery where most of the catabolic processes start with the surgery and extend through the postoperative period, it is likely that the preoperative nutritional status is not the most important factor determining the healing status of wound. The magnitude of the decrease in nutritional status and the body's ability to replenish the nutritional loss might have a significant role in the healing process.

\section{Malnutrition and intensive care unit stay and hospital stay}

In the present study, patients with low lymphocyte counts in the preoperative period and low albumin or prealbumin levels in the postoperative period were at risk of longer duration of hospital stay (Tables 9, 10). Similarly, Pedersen et al. [23] observed that malnourished patients (determined on the basis of weight loss, triceps skinfold thickness, and serum albumin and prealbumin levels) were more likely to have impaired wound healing, more medical complications (including cardiac-related complications), and longer hospitalization after surgery.

Nevertheless, hospital stay can be influenced by several aspects such as social and economic factors. Therefore, the significance of the duration of hospital stay with respect to nutritional parameters (preoperative low lymphocyte count and postoperative low prealbumin and albumin levels) observed in our study cannot be considered to be significant in the real clinical scenario.

We also found that low transferrin or low albumin or prealbumin levels in the postoperative period were associated with a higher risk for ICU admission (Table 8). To our knowledge, no other study has investigated or correlated this association.

Given the high prevalence of malnutrition in patients undergoing spine surgery and its impact on their outcomes along with the decrease in nutritional parameters, it is necessary that the surgeon should assess preoperative serum albumin levels, TLC, and transferrin levels and recommend patients whose levels are below the cutoff values to undergo a nutritional consultation. Similarly, in the postoperative period after major surgeries, it is necessary to care for the patients' nutritional intake.

If a patient is found to be malnourished, we recommend discussing with the patient about the possibility of delaying elective surgery until his/her nutritional status has improved. To our knowledge, no study has demonstrated improved outcomes as a result of correcting the nutritional status preoperatively; however, considering that the majority of literature support a link between malnutrition and increased morbidity after orthopedic surgery, we believe that addressing malnutrition preoperatively is a prudent approach in the attempt to reduce the risk of complications. Future studies should focus on whether improving preoperative nutritional status improves patient outcomes by decreasing the risk of morbidity after orthopedic surgery.

Patients undergoing major spine surgery are at risk of nutritional depletion. Therefore, it is necessary to assess both preoperative and postoperative nutritional status using serum albumin and prealbumin levels and also provide nutritional support to patients who exhibit a significant decrease in their nutritional status to reduce woundrelated complications. Basic history-taking, including food intake, combined with physical examination of the patient can help in the diagnosis of malnutrition. Laboratory tests, including a TLC and the assessment of albumin, prealbumin, and transferrin levels, may assist in the diagnosis but can be unreliable in the setting of trauma or perioperatively with the release of acute-phase proteins. 


\section{Limitations}

The sample size was small. Patients with different pathology, who were undergoing major surgery, were included. Patients with tumor and infection are more susceptible to nutritional depletion than patients with a degenerative pathology. A similar study on patients with specific pathologies would provide additional information.

\section{Conclusions}

The magnitude of the decrease in nutritional status due to surgery with respect to albumin and prealbumin levels is a significant predictor of wound-related complications, rather than a single nutritional parameter assessed at a point of time. Serum prealbumin is a useful biochemical parameter that can be used to assess acute changes in nutritional status.

\section{Conflict of Interest}

No potential conflict of interest relevant to this article was reported.

\section{References}

1. Studley HO. Percentage of weight loss: a basic indicator of surgical risk in patients with chronic peptic ulcer. 1936. Nutr Hosp 2001;16:141-3.

2. Giner M, Laviano A, Meguid MM, Gleason JR. In 1995 a correlation between malnutrition and poor outcome in critically ill patients still exists. Nutrition 1996;12:23-9.

3. Cuthbertson DP. Further observations on the disturbance of metabolism caused by injury, with particular reference to the dietary requirements of fracture cases. Br J Surg 1936;23:505-20.

4. Kaiser MJ, Bauer JM, Ramsch C, et al. Frequency of malnutrition in older adults: a multinational perspective using the mini nutritional assessment. J Am Geriatr Soc 2010;58:1734-8.

5. Lee EH, Baek SH, Chin JH, et al. Preoperative hypoalbuminemia is a major risk factor for acute kidney injury following off-pump coronary artery bypass surgery. Intensive Care Med 2012;38:1478-86.

6. Peersman G, Laskin R, Davis J, Peterson M. Infection in total knee replacement: a retrospective review of
6489 total knee replacements. Clin Orthop Relat Res 2001:15-23.

7. Bozic KJ, Lau E, Kurtz S, Ong K, Berry DJ. Patientrelated risk factors for postoperative mortality and periprosthetic joint infection in Medicare patients undergoing TKA. Clin Orthop Relat Res 2012;470:130-7.

8. Bozic KJ, Lau E, Kurtz S, et al. Patient-related risk factors for periprosthetic joint infection and postoperative mortality following total hip arthroplasty in Medicare patients. J Bone Joint Surg Am 2012;94:794-800.

9. Klein JD, Hey LA, Yu CS, et al. Perioperative nutrition and postoperative complications in patients undergoing spinal surgery. Spine (Phila Pa 1976) 1996;21:2676-82.

10. Jevsevar DS, Karlin LI. The relationship between preoperative nutritional status and complications after an operation for scoliosis in patients who have cerebral palsy. J Bone Joint Surg Am 1993;75:880-4.

11. Seibert DJ. Pathophysiology of surgical site infection in total hip arthroplasty. Am J Infect Control 1999;27:536-42.

12. Schuster JM, Rechtine G, Norvell DC, Dettori JR. The influence of perioperative risk factors and therapeutic interventions on infection rates after spine surgery: a systematic review. Spine (Phila Pa 1976) 2010;35(9 Suppl):S125-37.

13. Apisarnthanarak A, Jones M, Waterman BM, Carroll CM, Bernardi R, Fraser VJ. Risk factors for spinal surgical-site infections in a community hospital: a case-control study. Infect Control Hosp Epidemiol 2003;24:31-6.

14. Klekamp J, Spengler DM, McNamara MJ, Haas DW. Risk factors associated with methicillin-resistant staphylococcal wound infection after spinal surgery. J Spinal Disord 1999;12:187-91.

15. Sponseller PD, LaPorte DM, Hungerford MW, Eck K, Bridwell KH, Lenke LG. Deep wound infections after neuromuscular scoliosis surgery: a multicenter study of risk factors and treatment outcomes. Spine (Phila Pa 1976) 2000;25:2461-6.

16. Smith JS, Shaffrey CI, Sansur CA, et al. Rates of infection after spine surgery based on 108,419 procedures: a report from the Scoliosis Research Society Morbidity and Mortality Committee. Spine (Phila Pa 1976) 2011;36:556-63. 
17. Jensen JE, Jensen TG, Smith TK, Johnston DA, Dudrick SJ. Nutrition in orthopaedic surgery. J Bone Joint Surg Am 1982;64:1263-72.

18. Heller JG, Garfin SR. Postoperative infection of the spine. Semin Spine Surg 1990;2:268-82

19. Silber JS, Anderson DG, Vaccaro AR, et al. Management of postprocedural discitis. Spine J 2002;2:27987.

20. Smith JS, Shaffrey CI, Sansur CA, et al. Rates of infection after spine surgery based on 108,419 procedures: a report from the Scoliosis Research Society Morbidity and Mortality Committee. Spine (Phila Pa 1976) 2011;36:556-63.
21. Beiner JM, Grauer J, Kwon BK, Vaccaro AR. Postoperative wound infections of the spine. Neurosurg Focus 2003;15:E14.

22. Guo JJ, Yang H, Qian H, Huang L, Guo Z, Tang T. The effects of different nutritional measurements on delayed wound healing after hip fracture in the elderly. J Surg Res 2010;159:503-8.

23. Pedersen NW, Pedersen D. Nutrition as a prognostic indicator in amputations: a prospective study of 47 cases. Acta Orthop Scand 1992;63:675-8. 